\title{
ESTAFILOCOCOS COAGULASE POSITIVA EM QUEIJOS MINAS FRESCAL PRODUZIDOS EM AGROINDÚSTRIAS FAMILIARES
}

\section{Coagulase-positive Staphylococci in Minas Frescal cheeses produced in family agroindustries}

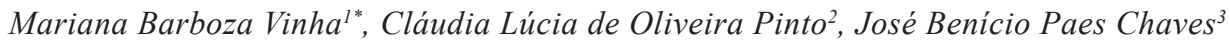

\section{RESUMO}

O objetivo deste estudo foi quantificar Estafilococos Coagulase Positiva (ECP) em queijos Minas Frescal, produzidos em seis queijarias não inspecionadas, sendo que destas, três delas utilizam leite cru e três utilizam leite pasteurizado. Foram coletadas 78 amostras, sendo 46 (24 na agroindústria e 22 no comércio) produzidas com leite pasteurizado e 32 ( 15 na agroindústria e 17 no comércio) fabricadas com leite cru. Queijos produzidos com leite pasteurizado apresentaram baixas contagens de $\operatorname{ECP}\left(1,0 \times 10^{1}\right.$ a $\left.2,0 \times 10^{3} \mathrm{UFC} / \mathrm{g}\right)$ e menor percentual de amostras não conformes $(6,5 \%)$, as quais podem ser justificas por contaminações pós-pasteurização, decorrente de falhas higiênico-sanitárias durante a fabricação e comercialização do produto. Queijos fabricados com leite cru apresentaram maior contaminação $\left(6,0 \times 10^{2}\right.$ a $\left.3,6 \times 10^{6} \mathrm{UFC} / \mathrm{g}\right)$ e maior percentual de amostras não conformes $(75,0 \%)$, podendo estas serem atribuídas à contaminação da matéria-prima. Queijos informais são potencialmente capazes de causar gastroenterite e oferecem risco à saúde pública. Agroindústrias familiares devem cumprir as exigências sanitárias a fim de oferecer produtos seguros aos consumidores, evitar surtos, regularizar a produção e ampliar a comercialização, proporcionando o desenvolvimento e consolidação desta importante atividade no meio rural.

Palavras-chave: pasteurização; inspeção; segurança alimentar; contaminação; S. aureus.

1 Instituto Capixaba de Pesquisa, Assistência Técnica e Extensão Rural, Rua Afonso Sarlo, 160, Bento Ferreira, 29052-010, Vitória, ES, Brasil. E-mail: mariana_vinha@hotmail.com

2 Empresa de Pesquisa Agropecuária de Minas Gerais (EPAMIG), Viçosa, MG, Brasil.

3 Universidade Federal de Viçosa, Viçosa, MG, Brasil.

* Autor para correspondência.

Recebido / Received: 21/03/2018

Aprovado / Approved: 14/09/2018 


\begin{abstract}
The aim of this work was to quantify Coagulase Positive Staphylococci (CPS) in Minas Frescal cheese produced in six non-inspected agroindustries, three of which use raw milk and three use pasteurized milk. Seventy-eight samples were collected, 46 of which (24 in agroindustry and 22 in commerce) were produced with pasteurized milk and 32 (15 in agroindustry and 17 in commerce) were made from raw milk. Cheeses produced with pasteurized milk had lower CPS counts $\left(1.0 \times 10^{1}\right.$ to $2.0 \mathrm{x}$ $\left.10^{3} \mathrm{UFC} / \mathrm{g}\right)$ and lower nonconforming samples (6.5\%), which may be justified by post-pasteurization contamination due to failures at hygienic-sanitary conditions during the manufacture and marketing of the product. Cheeses made from raw milk presented higher contamination $\left(6.0 \times 10^{2}\right.$ to $\left.3.6 \times 10^{6} \mathrm{CFU} / \mathrm{g}\right)$ and a higher percentage of nonconforming samples $(75 \%)$, which can be attributed to contamination of the raw material. Informal cheeses are potentially capable of causing gastroenteritis and offer risk to public health. Family agroindustries must comply with sanitary requirements in order to offer safe products to consumers, avoid outbreaks, regularize production and expand marketing, providing the development and consolidation of this important activity in rural areas.
\end{abstract}

Keywords: pasteurization; inspection; food safety; contamination; S. aureus.

\section{INTRODUÇ̃̃O}

O queijo Minas Frescal caracteriza-se como queijo semigordo de muito alta umidade. É obtido pela coagulação enzimática do leite, contemplada ou não à ação de bactérias lácticas, apresenta massa de consistência mole, não cozida e ligeiramente compactada (BRASIL, 1996; BRASIL, 2004). As características intrínsecas, tais como, alta atividade de água, o $\mathrm{pH}$ próximo à neutralidade, quando não utilizado fermento lático, e o elevado valor nutricional tornam o produto um substrato adequado para o desenvolvimento de microrganismos patogênicos como S. aureus (BARAN et al., 2017).

A legislação brasileira determina que o leite utilizado para fabricação de queijos seja pasteurizado. Raras exceções permitem-se o uso do leite cru na fabricação de queijos maturados e queijos artesanais produzidos em regiões tradicionais do país (BRASIL, 2017). O processo de pasteurização do leite destina-se a inativar bactérias patogênicas presentes na matéria-prima. No entanto, falhas no tratamento térmico e contaminações póspasteurização possibilitam a sobrevivência ou introdução de patógenos no produto, o que pode comprometer sua inocuidade e qualidade (FORSYTHE, 2013). Portanto, a fabricação de queijos, mesmo a partir de leite pasteurizado, deve estar de acordo com os requisitos gerais de higiene e de Boas Práticas de Fabricação (BPF) previamente estabelecidos (BRASIL, 1997), para evitar contaminações durante a produção e contribuir para produção de queijos seguros ao consumo humano.

A fabricação de queijo Minas Frescal a partir de leite cru é uma prática comum em pequenas queijarias do estado de Minas Gerais e de outras regiões do país. O uso de leite cru na fabricação de queijos implica em risco à saúde pública considerando a possibilidade de veiculação de patógenos alimentares, tais como, Listeria monocytogenes, Escherichia coli, S. aureus, Salmonella sp. e Campylobacter jejuni, além de zoonozes como Mycobacterium tuberculosis e Brucella abortus (VERRAES et al., 2015). Estudos 
relatam a baixa qualidade microbiológica e altas contagens microbianas em queijos produzidos com leite cru em diferentes regiões do país (KOMATSU et al., 2010; REZENDE et al., 2010; FERREIRA et al., 2011; OLIVEIRA et al., 2015; SOUZA et al., 2015). A pasteurização do leite é uma das dificuldades enfrentadas por produtores e o não cumprimento desta obrigatoriedade impossibilita a regularização das agroindústrias (CARVALHO et al., 2015). Queijos de produção artesanal, fabricados em estabelecimentos não inspecionados, apresentam qualidade microbiológica inferior aos produzidos industrialmente (SENGER; BIZANI, 2011; AMORIM et al., 2014), o que reforça a necessidade de regularização desses estabelecimentos. Além do uso de leite cru, produtores alegam que os altos custos com taxas e impostos, dificuldades em adequar a estrutura às exigências legais, procedimentos burocráticos e a necessidade de alteração da forma tradicional de produção dificultam a regularização dos estabelecimentos (CARVALHO et al., 2015). Além disso, muitos consumidores preferem o sabor dos queijos artesanais (não inspecionados) comercializados em feiras livres, embora eles desconheçam a precedência e os riscos inerentes ao consumo deste tipo de produto (AMORIM et al., 2014). A regularização desses estabelecimentos é necessária para comercialização dos produtos no mercado formal, amplia o volume de vendas e a renda familiar, fortalece a atividade econômica e proporciona queijos mais seguros para o consumo (FREITAS et al., 2013).

Staphylococcus aureus é uma bactéria Gram-positiva, produtora de enterotoxinas termoestáveis capazes de provocar intoxicações alimentares em humanos (LANDGRAF; DESTRO, 2013). Por muitos anos, S. aureus foi a única espécie do gênero considerada patogênica. Posteriormente, outras espécies produtoras de enterotoxinas e coagulase $(S$. hyicus e $S$. intermedius) foram identificadas e associadas à ocorrência de surtos alimen- tares, fato que resultou na modificação da legislação e inclusão de limites para presença de Estafilococos Coagulase Positiva (ECP), a qual inclui $S$. aureus (SILVA; GANDRA, 2004). O teste para detectar a produção de coagulase é uma ferramenta importante na diferenciação de espécies potencialmente patogênicas, visto que, há uma forte correlação entre a produção de coagulase e de enterotoxinas (LANDGRAF; DESTRO, 2013). No entanto, é necessário estar atento quanto a presença de Staphylococcus spp., visto que, outras espécies deste gênero, não produtoras de coagulase, são produtoras de enterotoxinas e, assim, são associadas a surtos de intoxicação alimentar (CARMO et al., 2002). Nunes et al. (2016) constataram presença de estafilococos coagulase negativos produtores de enterotoxinas em queijos Minas Frescal comercializados no sudeste do Brasil, o que reforça o risco de intoxicação alimentar por Staphylococcus sp. neste produto.

No Brasil, a produção do queijo é regulamentada pelo Ministério da Agricultura, Pecuária e Abastecimento (MAPA), que determina limite máximo de $10^{2} \mathrm{UFC} / \mathrm{g}$ de ECP para queijo Minas Frescal (BRASIL, 1996). Já a Agência Nacional de Vigilância Sanitária (ANVISA), responsável pela fiscalização dos queijos nos pontos de venda, estabelece limite máximo de $5 \times 10^{2} \mathrm{UFC} / \mathrm{g}$ de ECP para o queijo Minas Frescal comercializado no país (ANVISA, 2001). Contaminações por ECP acima dos limites oficiais foram relatadas em queijos frescos produzidos no Brasil (KOMATSU et al., 2010; FERREIRA et al., 2011; OLIVEIRA et al., 2015; SOUZA et al., 2017). O uso de leite oriundo de vacas com mastite, a falta de controle sanitário do rebanho, a ausência de pasteurização, a higiene inadequada durante a ordenha, as condições higiênico-sanitárias insuficientes ao longo da cadeia produtiva e os hábitos higiênicos inapropriados durante a manipulação contribuem para contaminação dos queijos (KÜMMEL et al., 2016; BARAN et al., 2017). 
A intoxicação alimentar associada a $S$. aureus resulta da ingestão do alimento contaminado com enterotoxinas sintetizadas durante o crescimento, quando o patógeno atinge contagens superiores a $10^{5} \mathrm{UFC} / \mathrm{g}$ (LANDGRAF; DESTRO, 2013). A produção de enterotoxinas, bem como a multiplicação de ECP, pode ocorrer em diferentes etapas da cadeia produtiva, desde a obtenção da matériaprima até a comercialização do queijo, e pode ser influenciada pela contaminação inicial, pelo uso de fermento lático, pelas condições de processamento e pela temperatura de armazenamento do produto (BARAN et al., 2017). As enterotoxinas estafilocócicas são proteínas de baixo peso molecular, resistentes ao tratamento térmico e às enzimas proteolíticas, o que dificulta sua inativação nos alimentos, portanto a pasteurização do leite é eficaz para inativação de Staphylococcus sp., mas não destrói as enterotoxinas pré-formadas (FORSTHYE 2013). Cabe ainda ressaltar, que essas proteínas podem ser produzidas na matéria-prima antes do tratamento térmico, o que implicará em risco de intoxicação mesmo após pasteurizar o leite (DIAS, 2012). Portanto, a adoção de medidas para evitar a produção de enterotoxinas na matéria-prima e nos queijos é necessária para garantir a segurança do produto. A implantação de boas práticas e o controle dos pontos críticos durante a fabricação dos queijos evitam a contaminação e multiplicação do patógeno. No entanto, uma das medidas mais importantes para evitar o crescimento de ECP em alimentos é a manutenção da cadeia de frio, desde a obtenção da matéria-prima, com o resfriamento do leite logo após ordenha, até o armazenamento do produto na residência do consumidor (EBERT, 2018).

Entre 2010 e 2016, S. aureus foi associado a 151 surtos relacionados ao consumo de leite ou de seus derivados no Brasil (ANVISA, 2017). Em Ouro Preto, MG, o consumo de queijo Minas contaminado por $S$. aureus $\left(9,3 \times 10^{7} \mathrm{UFC} / \mathrm{g}\right)$ provocou intoxica- ção alimentar em quatro pessoas de uma mesma família que apresentaram como sintomas náuseas, vômitos, diarreia e dores abdominais uma hora após ingerir o produto (SABIONI et al., 1988). Em Pará de Minas, MG, um surto que envolveu 15 indivíduos foi relacionado ao consumo de queijo Minas Frescal, fabricado artesanalmente, contaminado com toxina estafilocócica e Salmonella sp. (CERQUEIRA et al., 1994). Queijo Minas contaminado por enterotoxinas e $S$. aureus $\left(>10^{5} \mathrm{UFC} / \mathrm{g}\right.$ ) foi responsável por um surto de gastroenterite que acometeu 50 indivíduos em Manhuaçu, MG (CARMO et al., 2002). Em Passa Quatro, $\mathrm{MG}$, a presença de enterotoxinas e contagens de Estafilococos Coagulase Negativa (ECN), superiores a $10^{8} \mathrm{UFC} / \mathrm{g}$ foram constatadas em leite cru após 328 indivíduos ingerirem o produto e apresentarem episódios de diarreia e vômito (CARMO et al., 2002).

$\mathrm{O}$ risco de contaminação de queijos frescos com estafilococos produtores de enterotoxinas e a importância que este patógeno possui em relação à saúde pública justificam estudos para avaliar a ocorrência de contaminações em queijo Minas Frescal produzidos em pequenas queijarias. Portanto, objetivouse avaliar a ocorrência de estafilococos coagulase positiva em queijos Minas Frescal produzidos com leite cru e leite pasteurizado em agroindústrias familiares não inspecionadas, localizadas no município de Viçosa, MG.

\section{MATERIAL E MÉTODOS}

O estudo foi desenvolvido no município de Viçosa, MG, no período de janeiro a dezembro de 2008. Foram selecionadas, aleatoriamente, seis agroindústrias familiares não inspecionadas que fabricavam queijo Minas Frescal assistidas pela Empresa de Assistência Técnica e Extensão Rural (EMATER-MG). Dentre as seis agroindústrias selecionadas, três utilizavam leite pasteurizado como matéria-prima para a produção de queijo e três utilizavam leite cru. As amostras de 
queijo Minas Frescal foram coletadas nas agroindústrias e em seus respectivos pontos de venda, de forma independente. Na agroindústria, foram coletadas amostras com no máximo um dia de fabricação. Já no comércio, foram coletadas amostras de queijo com um a sete dias após a data de fabricação.

Foram realizadas oito coletas, sendo duas a cada estação do ano com intervalo mínimo de trinta dias entre elas. As coletas foram realizadas nas seis agroindústrias selecionadas e em seus respectivos pontos de venda. No entanto, no decorrer do trabalho, um produtor interrompeu a atividade e outro passou a fabricar o produto esporadicamente, o que comprometeu a coleta de algumas amostras. Dentre as 96 amostras inicialmente planejadas, foram coletadas 78 , sendo 46 produzidas com leite pasteurizado (24 provenientes da agroindústria e 22 do comércio) e 32 produzidas com leite cru (15 amostras procedentes da agroindústria e 17 do comércio).

As amostras caracterizavam-se pela unidade do produto (peça) em sua embalagem original e pesavam aproximadamente $500 \mathrm{~g}$. As análises microbiológicas foram realizadas no Laboratório de Microbiologia da Empresa de Pesquisa Agropecuária de Minas Gerais (EPAMIG), Unidade Regional da Zona da Mata, localizada no campus da Universidade Federal de Viçosa (UFV). A quantificação de ECP consistiu no plaqueamento em meio seletivo diferencial, ágar Baird-Parker (BP) suplementado com solução de gema de ovo e telurito de sódio, conforme protocolo (Brasil, 2003). As colônias típicas e atípicas foram submetidas à prova de coagulase para quantificação de ECP.

Os resultados após análise das amostras coletadas na fonte de produção foram comparados ao padrão do MAPA (BRASIL, 1996), e os resultados relativos aos queijos coletados no comércio foram comparados ao padrão da ANVISA (ANVISA, 2001). O percentual de amostras não conformes foi calculado por meio da razão entre o número de amostras em desacordo com o padrão e o número de amostras coletadas. Calculouse o percentual de amostras não conformes para queijos e acordo com o tipo de matériaprima utilizada (leite cru ou pasteurizado) e a agroindústria de origem.

\section{RESULTADOS E DISCUSSÃO}

Contaminações por ECP foram detectadas em 31 das 78 amostras de queijo Minas Frescal $(39,7 \%)$ produzidas em agroindústrias informais de Viçosa, as quais variaram de 10 a 3,6 x $10^{6} \mathrm{UFC} / \mathrm{g}$ (Tabela 1). Esse resultado é superior ao encontrado por Souza et al. (2017), os quais constataram que $32,0 \%$ (16/50) das amostras de queijo Minas Frescal, industriais e artesanais, comercializados em diferentes municípios da Zona da Mata Mineira, apresentavam contaminação superior ao limite estabelecido pela ANVISA. Apolinário et al. (2012) constataram um menor percentual de amostras não conformes $(16,1 \%)$ ao avaliar queijos fabricados em laticínios inspecionados localizados na mesma região. Esses resultados divergem dos observados por Garcia et al. (2016), que constataram $100 \%$ de amostras impróprias ao consumo, ao avaliar queijos frescos artesanais comercializados na região de Montes Claros, MG.

Neste trabalho, queijos produzidos com leite pasteurizado apresentaram melhor qualidade em relação a queijos produzidos com leite cru. A presença de ECP ocorreu em $15,2 \%$ (7/46) das amostras produzidas com leite pasteurizado, sendo que apenas $6,5 \%$ (3/46) estavam acima do limite estabelecido pelas legislações vigentes (BRASIL, 1996; ANVISA, 2001). A contagem de ECP em queijos produzidos com leite pasteurizado variou de $<10$ a $2,0 \times 10^{3} \mathrm{UFC} / \mathrm{g}$ e o patógeno não foi identificado em 36 das 46 amostras analisadas (Tabela 1). As agroindústrias avaliadas funcionavam sem registro nos órgãos 
fiscalizadores e apresentavam condições higiênico-sanitárias insuficientes, as quais foram observadas durante a coleta das amostras. Essa situação favorece a ocorrência de contaminações do produto após a pasteurização. Manipuladores de alimentos são reservatórios naturais de $S$. aureus e podem transmitir o patógeno durante a manipulação dos alimentos (DIAS, 2012). A presença de Staphylococcus sp., em superfícies de contato com alimento e de ECP em mesas utilizadas para fabricação de queijo, indicam que equipamentos e utensílios em condições higiênicas insatisfatórias, podem ser foco de contaminação cruzada (SILVA et al. 2011).

Alimentos tratados termicamente foram envolvidos em surtos de intoxicação estafilocócica, os quais foram associados às contaminações cruzadas dos produtos, seguida do acondicionamento a temperaturas superiores a $10{ }^{\circ} \mathrm{C}$ por tempo superior a 3 horas (DIAS, 2012; HENNEKINNE, 2018).

Além disso, cabe ressaltar que altas contaminações por ECP no leite resultam em produção de enterotoxinas (KÜMMEL et al. 2016). A presença da toxina estafilocócica em alimentos pasteurizados com baixas contagens do patógeno, ou mesmo ausência, justifica-se por sua resistência térmica, principal causa de surtos alimentares atribuídos a alimentos tratados termicamente em que se constatou ausência de patógenos (DIAS, 2012). Portanto, o uso de leite pasteurizado deve estar associado às boas condições higiênico-sanitárias em todas as etapas da cadeia produtiva e ao acondicionamento do produto sob refrigeração (EBERT, 2018).

Constatou-se que $75 \%$ (24/32) das amostras de queijo produzidos com leite cru apresentavam contagens de ECP superiores aos padrões oficiais (BRASIL, 1996; ANVISA, 2001), resultado indicativo de que estes produtos são impróprios ao consumo humano. As contaminações nestas amostras variaram entre $6,0 \times 10^{2}$ e $3,6 \times 10^{6} \mathrm{UFC} / \mathrm{g}$. A matéria-prima é a principal fonte de contaminação por ECP em queijos produzidos com leite cru e está relacionada à ocorrência de mastite clínica e subclínica no rebanho (KÜMMEL et al., 2016). Além do estado de saúde dos animais, a falta de higiene durante a ordenha, a limpeza insuficiente dos equipamentos e utensílios utilizados, a má qualidade da água e o armazenamento do leite a temperatura

Tabela 1 - Contagens de Estafilococos Coagulase Positiva (ECP) em queijos produzidos com leite cru e com leite pasteurizado, oriundos de agroindústrias não inspecionadas em Viçosa, MG

\begin{tabular}{c|cccc}
\hline \multirow{2}{*}{$\begin{array}{c}\text { Contagem de } \\
\text { ECP }(\mathrm{UFC} / \mathrm{g})\end{array}$} & \multicolumn{2}{|c}{$\begin{array}{c}\text { Queijos fabricados com } \\
\text { leite pasteurizado }\end{array}$} & \multicolumn{2}{c}{$\begin{array}{c}\text { Queijos fabricado com } \\
\text { leite cru }\end{array}$} \\
\cline { 2 - 5 } & $\begin{array}{c}\text { Número de } \\
\text { amostras }\end{array}$ & $\begin{array}{c}\text { Percentual de } \\
\text { amostras }\end{array}$ & $\begin{array}{c}\text { Número de } \\
\text { amostras }\end{array}$ & $\begin{array}{c}\text { Percentual de } \\
\text { amostras }\end{array}$ \\
\hline Menor que 10 & 39 & $84,8 \%$ & 8 & $25,0 \%$ \\
10 a $1,0 \times 10^{2}$ & 3 & $6,5 \%$ & 0 & $0,0 \%$ \\
$1,1 \times 10^{2}$ a $1,0 \times 10^{3}$ & 1 & $2,2 \%$ & 2 & $6,3 \%$ \\
$1,1 \times 10^{3}$ a $1,0 \times 10^{4}$ & 3 & $6,5 \%$ & 8 & $25,0 \%$ \\
$1,1 \times 10^{4}$ a $1,0 \times 10^{5}$ & 0 & $0,0 \%$ & 3 & $9,4 \%$ \\
$1,1 \times 10^{5}$ a $1,0 \times 10^{6}$ & 0 & $0,0 \%$ & 10 & $31,3 \%$ \\
$1,1 \times 10^{6}$ a $1,1 \times 10^{7}$ & 0 & $0,0 \%$ & 1 & $3,1 \%$ \\
Total & 46 & $100,0 \%$ & 32 & $100,0 \%$ \\
\hline
\end{tabular}


inadequada contribuem para presença de patógenos na matéria-prima (LEIRA et al., 2018). Alguns subtipos de $S$. aureus, presentes na produção primária do leite, foram capazes de contaminar e persistir em ambientes de fabricação, sendo isolados em queijos, 14 dias após a produção. Portanto, o controle deste microrganismo na cadeia láctea requer ações preventivas desde a produção leiteira, para evitar a contaminação do produto final pelo patógeno ou suas toxinas (KÜMMEL et al., 2016).

Contaminações por ECP superiores às identificadas neste estudo foram relatadas por outros autores. Garcia et al. (2016) identificaram que $100 \%$ dos queijos frescos artesanais comercializados na região do norte de Minas não atendiam ao padrão da ANVISA para ECP. Oliveira et al. (2015) identificaram contagens da ordem de $10^{5} \mathrm{UFC} / \mathrm{g}$ em todas as amostras coletadas na feira livre de Uruaçu, Goiás. Em Araxá, MG, Souza et al. (2015) constataram que 93,3\% das amostras de queijo Minas artesanal fabricadas com leite cru estavam em desacordo com o limite estabelecido para ECP, com contaminações variáveis entre $3,0 \times 10^{2}$ a 2,0 x $10^{7} \mathrm{UFC} / \mathrm{g}$. Em Uberlândia, MG, 88\% dos queijos avaliados por Komatsu et al. (2010) apresentaram contagens de ECP superior ao limite oficial, as quais variaram entre $8,9 \times 10^{3} \mathrm{e}$ $6,4 \times 10^{5} \mathrm{UFC} / \mathrm{g}$. Em Seropédica, RJ, Zegarra et al. (2009) detectaram $S$. aureus em $60 \%$ das amostras de queijos, bem como no leite e nos utensílios utilizados em sua fabricação. Resultado inferior aos observados neste estudo foi constato por Senger; Bizani (2011), que identificaram menor percentual $(40 \%)$ de amostras não conformes em queijo Minas Frescal de produção artesanal comercializados em feiras livres de Canoas, RS.

Queijos provenientes das agroindústrias B e C apresentaram melhor qualidade, visto que, todas as amostras avaliadas estavam abaixo dos padrões estabelecidos pelo MAPA e pela ANVISA (Tabela 2). Três amostras pro- venientes da agroindústria A (duas coletadas na produção e uma no comércio) estavam em desacordo com os padrões oficiais (BRASIL, 1996; ANVISA, 2001) e, portanto, impróprias ao consumo. Observou-se, durante a coleta das amostras, que os queijos eram fabricados na varanda da residência, o produtor não havia realizado treinamento sobre Boas Práticas de Manipulação, não havia tratamento adequado para água utilizada e os utensílios utilizados não eram higienizados corretamente. As irregularidades observadas justificam a ocorrência de contaminações após pasteurização do leite, e ainda reforçam a necessidade de implementação das BPF para obtenção de queijos de melhor qualidade microbiológica.

Os queijos produzidos pela agroindústria $\mathrm{D}$ apresentaram maior percentual de não conformidade $(87,5 \%)$ e maior contaminação por ECP $\left(3,6 \times 10^{6} \mathrm{UFC} / \mathrm{g}\right)$ (Tabela 2$)$. Constatou-se que 68,7\% (11/16) das amostras fabricadas neste estabelecimento apresentavam contaminações por ECP superiores a $10^{5} \mathrm{UFC} / \mathrm{g}$. Populações microbianas desta magnitude são capazes de produzir de 300 a $500 \eta \mathrm{g} / \mathrm{kg}$ de enterotoxina, quantidade suficiente para provocar intoxicação alimentar (FORSYTHE, 2013). Contaminações dessa ordem, acompanhada ou não da presença de enterotoxinas, foram observadas em alimentos associados a surtos de intoxicação alimentar em Minas Gerais, o que reforça a relação entre altas contaminações, presença de enterotoxinas e ocorrência de surtos alimentares (DIAS, 2012). Diante dessas informações, pode-se afirmar que os queijos oriundos do estabelecimento D são suscetíveis à presença dessas toxinas e são potencialmente capazes de provocar intoxicações alimentares.

As agroindústrias E e F também apresentaram alto percentual de amostras com contagens superiores aos padrões estabelecidos pelo MAPA e pela ANVISA, ou seja impróprias para o consumo. No entanto, nenhuma das amostras oriundas destes estabe- 
Tabela 2 - Amostras de queijos Minas Frescal produzidos com leite pasteurizado ou leite cru, em agroindústrias familiares de Viçosa (MG)

\begin{tabular}{|c|c|c|c|c|c|}
\hline \multirow[b]{2}{*}{ Matéria-Prima } & \multirow[b]{2}{*}{ Agroindústria } & \multicolumn{2}{|c|}{ Produção } & \multicolumn{2}{|c|}{ Comércio } \\
\hline & & $\begin{array}{c}\text { Variação da } \\
\text { contagem } \\
\text { (UFC/g) }\end{array}$ & $\begin{array}{c}\text { Amostras } \\
\text { não conforme } \\
(\%)\end{array}$ & $\begin{array}{l}\text { Variação da } \\
\text { contagem } \\
(\mathrm{UFC} / \mathrm{g})(\%)\end{array}$ & $\begin{array}{c}\text { Amostras } \\
\text { não conforme } \\
(\%)\end{array}$ \\
\hline \multirow{4}{*}{$\begin{array}{c}\text { Leite } \\
\text { pasteurizado }\end{array}$} & A & $<10$ a $2,0 \times 10^{3}$ & $25,0 \%(2 / 8)$ & $<10$ a $2,1 \times 10^{3}$ & $12,5 \%(1 / 8)$ \\
\hline & B & $<10$ a 10 & $0 \%(0 / 8)$ & $<10$ & $0 \%(0 / 8)$ \\
\hline & $\mathrm{C}$ & $<10$ & $0 \%(0 / 8)$ & $<10$ a $1,5 \times 10^{2}$ & $0 \%(0 / 5)$ \\
\hline & Total & $<10$ a $2,0 \times 10^{3}$ & $8,3 \%(2 / 24)$ & $<10$ a $2,1 \times 10^{3}$ & $4,8 \%(1 / 21)$ \\
\hline \multirow{4}{*}{$\begin{array}{l}\text { Leite } \\
\text { cru }\end{array}$} & $\mathrm{D}$ & $<10$ a $6,5 \times 10^{5}$ & $87,5 \%(7 / 8)$ & $<10$ a $3,6 \times 10^{6}$ & $75,0 \%(6 / 8)$ \\
\hline & $\mathrm{E}$ & $<10$ a $7,5 \times 10^{4}$ & $75,0 \%(3 / 4)$ & $<10$ a $4,0 \times 10^{4}$ & $71,4 \%(5 / 7)$ \\
\hline & $\mathrm{F}$ & $<10$ a $5,0 \times 10^{3}$ & $66,7 \%(2 / 3)$ & $<10$ a $5,3 \times 10^{3}$ & $50,0 \%(1 / 2)$ \\
\hline & Total & $<10$ a $6,5 \times 10^{5}$ & $80,0 \%(12 / 15)$ & $<10$ a $3,6 \times 10^{6}$ & $70,6 \%(12 / 17)$ \\
\hline
\end{tabular}

lecimentos apresentou contagens superiores a $10^{5} \mathrm{UFC} / \mathrm{g}$ (Tabela 2). A produção de enterotoxinas ocorre em temperaturas que variam de 10 a $48^{\circ} \mathrm{C}$, sendo a maior velocidade de produção entre 40 e $45^{\circ} \mathrm{C}$ (LANDGRAF; DESTRO, 2013). Assim sendo, pode ocorrer aumento das contaminações, em função da multiplicação do patógeno, e produção de enterotoxinas caso esses queijos sejam armazenados a temperaturas superiores a $10{ }^{\circ} \mathrm{C}$. A produção de queijos nos estabelecimentos $\mathrm{E}$ e F era uma atividade secundária, fabricavase de 1 a $2 \mathrm{Kg}$ de queijo por dia para comercialização aos sábados na feira livre do município. Além disso, a baixa produção de leite nas propriedades restringia a fabricação do queijo aos períodos de produção de matéria-prima. No decorrer do trabalho, a agroindústria $\mathrm{F}$ interrompeu a atividade, pois a fabricação de queijos tornou-se inviável pela necessidade de investimentos para atender as exigências legais. Os resultados deste estudo reforçam que a comercialização de queijos, produzidos com leite cru em estabelecimentos não inspecionados, representa risco à saúde, mesmo quando realizada esporadicamente. A maior contaminação por ECP foi observada em uma amostra de queijo Minas Frescal produzida com leite cru e coletada no comércio (Tabela 2). A maior parte das amostras foi coletada na feira livre (17/38), seguida de mercearias $(11 / 38)$, quitandas $(5 / 38)$ e açougues (5/38). Durante a coleta dos queijos, foram observadas irregularidades nas condições de comercialização dos queijos, tais como, limpeza insuficiente dos balcões, acúmulo de gelo no equipamento, exsudação excessiva de soro nas embalagens e armazenamento concomitante com carnes e garrafas. A maior parte das amostras $(55,7 \%)$ estava acondicionada em temperaturas inferiores a $10{ }^{\circ} \mathrm{C}$, sendo que $44,7 \%$ delas eram comercializadas à temperatura ambiente. Nas feiras livres, o produto permanecia por longos períodos em caixas de isopor ou à temperatura ambiente. Além disso, a manipulação de dinheiro e outros produtos durante a comercialização são fatores que comprometem a qualidade do queijo.

$\mathrm{O}$ alto percentual de não conformidades $(70,6 \%)$ e as contagens de ECP superiores a $10^{3} \mathrm{UFC} / \mathrm{g}$ observados em amostras coletadas no comércio (Tabela 2) também são indicativos de condições higiênico-sanitárias 
insuficientes de comercialização, o que torna o produto susceptível à contaminações e à produção de toxina estafilocócica. Em estudos semelhantes, há relatos de contaminações e percentual em amostras não conformes superiores aos constatados neste estudo. Em Uberlândia, MG, Rezende et al., (2010) avaliaram os aspectos sanitários de queijos comercializados nas feiras livres e concluíram que todas as amostras estavam acima do padrão oficial estabelecido para ECP, com contagens entre $2,3 \times 10^{4} \mathrm{e}>2,5 \times 10^{7} \mathrm{UFC} / \mathrm{g}$. Em Uruaçu, GO, Oliveira et al. (2015) identificaram que $100 \%$ das amostras de queijos Minas Frescal comercializadas na feira livre estavam impróprias para o consumo, com contagens da ordem de $10^{5} \mathrm{UFC} / \mathrm{g}$. As condições de exposição dos queijos durante a comercialização foram consideradas possíveis causas de contaminações cruzadas, uma vez que o produto ficava disponível para venda em bancas de madeira à temperatura ambiente, era manipulado com outros alimentos e não havia local para higienização das mãos (REZENDE et al., 2010).

\section{CONCLUSÕES}

$\mathrm{O}$ alto percentual de não conformidades constatadas em queijos produzidos com leite cru em agroindústrias familiares não inspecionadas, indica que o consumo deste tipo de produto representa risco potencial à saúde do consumidor. A pasteurização do leite contribui para redução da contaminação por ECP, a qual deve estar ainda associada às práticas higiênicas durante a manipulação, para evitar contaminações cruzadas. Os produtores devem receber orientações sobre a legislação sanitária, compreender sua importância e buscar alternativas para cumprila, a fim de regularizar suas queijarias e oferecer ao consumidor produtos mais seguros. A fiscalização sanitária deve ser efetiva nos pontos de venda e nas agroindústrias, para garantir o cumprimento das exigências legais e reduzir a oferta de queijos impróprios ao consumo.

\section{AGRADECIMENTOS}

À Fundação de Amparo à Pesquisa do Estado de Minas Gerais (FAPEMIG) pelo apoio financeiro e ao Conselho Nacional de Desenvolvimento Científico e Tecnológico (CNPq) pela concessão da bolsa de estudos.

\section{REFERÊNCIAS}

AMORIM, A. L. B. C. et al. Avaliação da qualidade microbiológica de queijos do tipo Minas padrão de produção industrial, artesanal e informal. Revista do Instituto Adolfo Lutz, v. 73, n. 4, p. 364-367, 2014.

AGÊNCIA NACIONAL DE VIGILÂNCIA SANITÁRIA (ANVISA). Doenças transmitidas por alimentos, situação Epidemiológica, 2017. Banco de dados 2000 a 2017. Disponível em: <http://portalms.saude.gov. br/saude-de-a-z/doencas-transmitidas-poralimentos/situacao-epidemiologica $>$. Acesso em: 08 fev. 2018.

AGÊNCIA NACIONAL DE VIGILÂNCIA SANITÁRIA (ANVISA). RDC $\mathrm{n}^{\circ} 12$, de 02 de janeiro de 2001. Regulamento técnico sobre padrões microbiológicos para alimentos. Diário Oficial da República Federativa do Brasil, Brasília, 10 jan. 2001. Seção 1, p. 45-53.

APOLINÁRIO, T. C. C.; SANTOS, G. S.; LAVORATO, J. A. A. Avaliação da qualidade microbiológica do queijo Minas Frescal produzido por laticínios do estado de Minas Gerais. Revista do Instituto de Laticínios Cândido Tostes, v. 9, n. 6, p. 433-442, 2014.

BARAN, A. et al. A review on the presence of Staphylococcus aureus in cheese. Turkish 
Journal of Nature and Science, v. 6, n. 2, p. 100-105, 2017.

BRASIL. Decreto n. 9.013, de 29 de março de 2017. Regulamenta a Lei $\mathrm{n}^{0} 1.283$, de 18 de dezembro de 1950 , e a Lei $n^{\circ} 7.889$, de 23 de novembro de 1989, que dispõem sobre a inspeção industrial e sanitária de produtos de origem animal. Diário Oficial da República Federativa do Brasil, Brasília, 30 mar. 2017. Seção 1, p. 3. 2017.

BRASIL. Instrução Normativa $n^{\circ}$ 62, de 26 de agosto de 2003. Oficializa os Métodos Analíticos Oficiais para Análises Microbiológicas para Controle de Produtos de Origem Animal e Água. Diário Oficial da República Federativa do Brasil, Brasília, 18 set. 2003. Seção 1, p. 14.

BRASIL. Portaria ${ }^{\circ} 146$, de 07 de março de 1996. Aprova Regulamentos Técnicos de Identidade e Qualidade dos Produtos Lácteos. Diário Oficial da República Federativa do Brasil, Brasília, 11 mar. 1996. Seção 1, p. 3977.

BRASIL. Portaria $n^{\circ} 368$, de 04 de setembro de 1997. Aprova o Regulamento Técnico sobre as condições Higiênico-Sanitárias e de Boas Práticas de Fabricação para Estabelecimentos Elaboradores/ Industrializadores de Alimentos. Diário Oficial da República Federativa do Brasil, Brasília, 08 set. 1997. Seção 1, p. 196.

BRASIL. Instrução Normativa $n^{\circ} 4$, de 1 de março de 2004. Altera o regulamento técnico para fixação de identidade e qualidade do queijo Minas Frescal. Diário Oficial da República Federativa do Brasil, Brasília, 05 mar. 2004. Seção 1, p. 5.

CARMO, L. S.; DIAS, R. S.; LINARDI, V. R. Food poisoning due to enterotoxigenic strains of Staphylococcus present in Minas cheese and raw milk in Brazil. Food Microbiology, v. 19, n. 1, p. 9-4, 2002.
CARVALHO, M. M; LINDNER J. D.; FARIÑA, L. O. A produção de queijo colonial artesanal no município de Seara, estado de Santa Catarina, frente à legislação brasileira. Revista do Instituto de Laticínios Cândido Tostes, v. 70, n. 5, p. 253-261, 2015.

CERQUEIRA, M. M. O. P. et al. Surto epidêmico de toxinfecçäo alimentar envolvendo queijo tipo Minas Frescal em Pará de Minas. Arquivo Brasileiro de Medicina Veterinária e Zootecnia, v. 46, n. 6, p. 723-8, 1994.

DIAS, R. S. Surtos de intoxicação alimentar por linhagens enterotoxigênicas de Staphylococcus ocorridos em diferentes municípios mineiros. NBC-Periódico Científico do Núcleo de Biociências, v. 2, n. 4, p. 1-6, 2012.

EBERT, M. Hygiene principles to avoid contamination/cross-contamination in the kitchen and during food processing. In: FETSCH, A. Staphylococcus aureus. London: Elsevier, 2018. p. 217-234.

FERREIRA, R. M. et al. Pesquisa de Staphylococcus coagulase positiva em queijo Minas Frescal artesanal. PUBVET, v. 5, n. 5, art. 1021, 2011.

FORSYTHE, S. J. Microbiologia da Segurança dos Alimentos. Porto Alegre: Artmed, 2013. 602p.

FREITAS, J. F, et. al. Orientações para formalização fiscal, ambiental e sanitária. Plano de Desenvolvimento da Agroindústria Familiar e do Empreendedorismo Rural - Agrolegal. Vitória: Agência de Desenvolvimento das Micro e Pequenas Empresas e do Empreendedorismo, ADERES, 2013. 65p.

GARCIA, J. K. S. et al. Qualidade microbiológica de queijos frescos artesanais comercializados na região do norte de Minas Gerais. Caderno de Ciências Agrárias, v. 8, n. 2, p. 58-65, 2016. 
HENNEKINNE, J. A. Staphylococcus aureus as a leading cause of foodborne outbreaks worldwide. In: FETSCH, A. Staphylococcus aureus. London: Elsevier. 2018. p. 129-146.

KOMATSU, R. S. et al. Ocorrência de Staphylococcus coagulase positiva em queijos Minas Frescal produzidos em Uberlândia-MG. Bioscience Journal, v. 26, n. 2, p. 316-321, 2010.

KÜMMEL J. et al. Staphylococcus aureus entrance into the dairy chain: tracking $S$. aureus from dairy cow to cheese. Frontiers in Microbiology, v. 7, n. 1603, 2016.

LANDGRAF M.; DESTRO M. T. Staphylococcal Food Poisoning. In: MORRIS, G. J.; POTTER, M. E. Foodborne Infections and Intoxications. Atlanta: Elsevier, 2013. p. 398-400.

LEIRA, M. E. et al. Fatores que alteram a produção e a qualidade do leite: Revisão. PUBVET, v. 12, n. 5, p. 1-13, 2018.

NUNES, R. S. C. et al. Identification and molecular phylogeny of coagulase-negative staphylococci isolates from Minas Frescal cheese in southeastern Brazil: Superantigenic toxin production and antibiotic resistance. Jounal of Dairy Science, v. 99, p. 2641-2653, 2016.

OLIVEIRA, K. M. L. et al. Presença de Staphylococcus aureus em queijos artesanais comercializados na cidade de Uruaçu-Goiás. Fasem Ciências, v. 8, n. 2, p. 63-71, 2015.

REZENDE, P. H. L et al. Aspectos sanitários do queijo minas artesanal comercializado em feiras livres. Revista Instituto de Laticínios Cândido Tostes, n. 377, v. 65, p. 36-42, 2010.

SABIONI, J. G.; HIROOKA, E. Y.; SOUZA,
M. L. R. Intoxicação alimentar por queijo Minas contaminado com Staphylococcus aureus. Revista de Saúde Pública, v. 22, n. 5, p. 458-61, 1988.

SENGER, A. E. V.; BIZANI, D. Pesquisa de Staphylococcus aureus em queijo Minas Frescal, produzido de forma artesanal e industrial, comercializado na cidade de Canoas/RS, Brasil. Revista de Ciências Ambientais, v. 5, n. 2, p. 25-42, 2011.

SILVA, W. P.; GANDRA, E. A. Estafilococos coagulase positiva: patógenos de importância em alimentos. Higiene Alimentar, v. 18, n. 122, p. 32-40, 2004.

SILVA, N. B. N. et al. Avaliação microbiológica de equipamentos e utensílios utilizados em laticínios da região de Rio Pomba - MG. Revista do Instituto de Laticínios Cândido Tostes, v. 66, n. 5, p. 5-1, 2011.

SOUZA, I. A. et al. Qualidade microbiológica de queijo Minas Frescal comercializado na Zona da Mata Mineira. Revista do Instituto de Laticínios Cândido Tostes, v. 72, n. 3, p. 152-162, 2017.

SOUZA, V. et al. Estirpes de Staphylococcus aureus isoladas de queijo Minas artesanal de Araxá. Ars Veterinária, v. 31, n. 1, p. 19-23, 2015.

VERRAES, C. et al. A review of the microbiological hazards of dairy products made from raw milk. International Dairy Journal, v. 50, n. 1, p. 32-44, 2015.

ZEGARRA, J. J. Q. et al. Pesquisa de microrganismos em utensílios, leite e queijos de produção artesanal em unidades de produção familiar no município de Seropédica, Rio de Janeiro. Ciência Animal Brasileira, v. 10, n. 1, p. 312-321, 2009. 